NBER WORKING PAPER SERIES

\title{
THE EFFECTS OF FINANCIAL AID GRANT OFFERS ON POSTSECONDARY EDUCATIONAL OUTCOMES: NEW EXPERIMENTAL EVIDENCE FROM THE FUND FOR WISCONSIN SCHOLARS
}

\author{
Deven E. Carlson \\ Felix Elwert \\ Nicholas Hillman \\ Alex Schmidt \\ Barbara L. Wolfe \\ Working Paper 26419 \\ http://www.nber.org/papers/w26419 \\ NATIONAL BUREAU OF ECONOMIC RESEARCH \\ 1050 Massachusetts Avenue \\ Cambridge, MA 02138 \\ November 2019
}

\begin{abstract}
We thank the Executive Director and Board of the Fund for Wisconsin Scholars, the Wisconsin Department of Public Instruction, The University of Wisconsin System, Higher Educational Aids Board and the Institute for Research on Poverty for their cooperation with this project including making the data available. We thank FFWS for funding the cleaning and merging of data elements. We also gratefully acknowledge use of the services and facilities of the Center for Demography and Ecology at the University of Wisconsin-Madison, funded by NICHD Center Grant P2C HD047873. The views expressed herein are those of the authors and do not necessarily reflect the views of the National Bureau of Economic Research.
\end{abstract}

NBER working papers are circulated for discussion and comment purposes. They have not been peer-reviewed or been subject to the review by the NBER Board of Directors that accompanies official NBER publications.

(C) 2019 by Deven E. Carlson, Felix Elwert, Nicholas Hillman, Alex Schmidt, and Barbara L. Wolfe. All rights reserved. Short sections of text, not to exceed two paragraphs, may be quoted without explicit permission provided that full credit, including $(\odot$ notice, is given to the source. 
The Effects of Financial Aid Grant Offers on Postsecondary Educational Outcomes: New Experimental Evidence from the Fund for Wisconsin Scholars

Deven E. Carlson, Felix Elwert, Nicholas Hillman, Alex Schmidt, and Barbara L. Wolfe

NBER Working Paper No. 26419

November 2019

JEL No. I20,I24

\begin{abstract}
In this pre-registered study, we analyze the effects of need-based financial aid grant offers on the educational outcomes of low-income college students based on a large-scale randomized experiment $(n=48,804)$. We find evidence that the grant offers increase two-year persistence by 1.7 percentage points among four-year college students. The estimated effect on six-year bachelor's degree completion is of similar size - 1.5 percentage points-but is not statistically significant. Among two-year students, we find positive-but not statistically significant-effects on persistence and bachelor's degree completion (1.2 and 0.5 percentage points, respectively). We find little evidence that effects vary by cohort, race, gender or the prior receipt of food stamps. However, further exploratory results do suggest that the offers reduce associate's degree completion rates for two-year community college students by around 3 percentage points, with no statistically significant evidence of effects on technical college students. We also estimate that the effects of actually receiving grant money are very similar, though slightly greater than the effects of merely receiving a grant offer. Overall, our results show only very small effects of the needbased grant offers on college students' trajectories towards degree completion.
\end{abstract}

Deven E. Carlson

University of Oklahoma

Department of Political Science

205 Dale Hall Tower

455 W. Lindsey St.

Norman, OK 73019

decarlson@ou.edu

Felix Elwert

University of Wisconsin-Madison

4426 Sewell Social Sciences

Madison, WI 53706

elwert@wisc.edu

Nicholas Hillman

University of Wisconsin-Madison

1000 Bascom Mall, 249

Madison, WI 53706

nwhillman@wisc.edu
Alex Schmidt

University of Wisconsin-Madison

8128 Social Science Bldg.

Madison, WI 53706

ajschmidt6@wisc.edu

Barbara L. Wolfe

3458 Social Science Building

University of Wisconsin

Madison, WI 53706

and NBER

BWolfe@wisc.edu

A randomized controlled trials registry entry is available at https://www.socialscienceregistry.org/trials/3198 
The Effects of Financial Aid Grant Offers on Postsecondary Educational Outcomes: New Experimental Evidence from the Fund for Wisconsin Scholars

\section{Introduction}

A college education can be a path to upward mobility for children born into low-income families. But over the past few decades, college access and completion gaps have widened between low-income and high-income students (Bailey \& Dynarski, 2011), and disparate graduation rates between colleges have garnered attention (Leonhardt \& Chinoy, 2019). Finances and students' ability to pay the rising price of tuition are candidate explanations for these gaps. Since 2000, the average tuition at public four-year colleges has doubled to $\$ 10,230$ (Ma, Baum, Pender, \& Libassi, 2018). To help cover rising expenses, states and the federal government invest over $\$ 35$ billion annually in “need-based" aid targeted to low-income students, but this aid is not keeping pace with rising tuition levels. For example, the federal Pell Grant is the nation's primary need-based aid program, yet its average award $(\$ 3,700)$ covers a small and shrinking share of tuition (Baum, Ma, Pender, \& Bell, 2015). To supplement these efforts, some colleges and private philanthropic organizations (e.g., Bill and Melinda Gates Foundation, Susan Thompson Buffet Foundation, etc.) offer additional financial aid for low-income students.

This study presents a randomized evaluation of the effects of a financial aid program for low-income students in Wisconsin. Created in 2007 with a philanthropic gift of \$167 million from John and Tashia Morgridge, the Fund for Wisconsin Scholars (FFWS) provides scholarships to Pell-eligible students attending public postsecondary institutions in Wisconsin. Since Pell Grants only cover a portion of the total costs of Wisconsin public colleges (see Table 1), the objective of the FFWS program is to provide financial relief in order to increase persistence and graduation rates among low-income students who are already enrolled. 
[Insert Table 1 here]

In contrast to most other studies of financial aid programs, the randomization of the FFWS offer among eligible students allows for the identification of the causal effects of the FFWS program on subsequent outcomes. In this study, our primary aims are to determine whether the grant offered by the FFWS program, and the aid actually received by students, increased students' probability of persisting into the second year and completing a bachelor's degree within six years. As secondary aims, we also examine whether the effects on these primary outcomes varied by student characteristics, and we explore effects on secondary outcomes, including three-year associate’s degree completion, transferring to a four-year university, and four-year bachelor's degree completion.

All analyses reported in this paper follow our detailed pre-analysis plan, which was registered with the American Economic Association prior to the receipt of outcomes data. ${ }^{1}$ All deviations from the pre-registered plan are explicitly noted in the text or endnotes.

In the following, we first describe the FFWS program and experimental design and review past research on financial aid programs. We then describe our choices for variable creation and statistical analysis. We report two broad sets of results: first, our experimental evaluation of the effect of receiving an FFWS grant offer; second, instrumental variables estimates of the effect of actually receiving FFWS aid.

\section{The Fund for Wisconsin Scholars}

The FFWS intervention is an offer of need-based financial aid for Pell-eligible Wisconsin college students. Around 550 to 650 two- and four-year students are randomly selected to receive the grant offer every year, starting in 2008. Students in public two-year colleges (e.g., technical college or community colleges) can receive up to $\$ 1,800$ per academic year. Early in the 
program, students attending four-year universities could receive up to $\$ 3,500$ per academic year; recently, that amount increased to $\$ 4,000$ (in the 2015-16 school year). Students can receive FFWS awards for a maximum of five years. On average, two-year college students receive \$1,232 during their first year (2009-2015 cohorts) and \$3,253 over five years (2009-2012 cohorts), while four-year college students receive \$2,914 during their first year (2009-2015 cohorts) and \$9,512 over five years (2009-2012 cohorts).

To be eligible for the grant offer, a student must be a Wisconsin resident who graduated from a public high school in the state and is under 21 years old. Students must also be pursuing a first-degree program (unless moving from an associate’s degree program to a bachelor's program) and they must be enrolled full-time in a two-year college in the Wisconsin Technical College System (WTCS) or a two- or four-year college in the University of Wisconsin System (UWS). Finally, students must be eligible for the federal Pell Grant, which means they must complete the Free Application for Federal Student Aid (FAFSA) and be identified for FFWS eligibility by their campus' financial aid office. After receiving a written grant offer, the following additional conditions must be met in order to receive FFWS funds: 1) students must accept the grant offer and provide additional information to confirm their eligibility, and 2) students must have remaining unmet financial need (described further below). Students remain eligible to receive FFWS funds every semester for 10 semesters as long as they continue to fulfill the above eligibility requirements, refile the FAFSA each year, and meet the college's satisfactory academic progress standards. Students remain eligible when they transfer to another eligible public two-/four-year college (UWS or WTCS).

The randomization process for the grant offers begins when college financial aid offices send lists of eligible students to the Wisconsin Higher Educational Aids Board (HEAB) at the 
beginning of each school year. HEAB compiles all eligible four-year students into one pool, and all eligible two-year students into another pool, and conducts a blocked randomization within each pool. In each randomization block, HEAB randomly selects between 550 and 650 students for the treatment condition with the goal that 500 students accept the award. From 2009 through 2015 (the cohorts under study), 48,804 students were entered into the randomization pool and 8,407 were randomly selected to receive the grant offer.

Using this sample of students, we evaluate the effects of the FFWS offer on the primary outcomes of persistence and degree completion. This focus is justified because the FFWS offer — not the receipt of FFWS aid — is the main intervention. The FFWS only provides aid to students with remaining unmet need, where unmet need is equal to total cost of attendance minus Expected Family Contribution (EFC) and aid from other grant or scholarship programs. The FFWS grant offer cannot supplant any other form of grant aid, and the dollar amount of a student's FFWS grant cannot exceed her unmet need. If a student’s tuition bill is already covered, then the FFWS award can either be paid directly to the student to be used for allowable non-tuition expenses including books, supplies, transportation, room and board, and dependent care, or it can be used to replace loans in the student's aid package. If a student's need is fully met by other grant aid in a given semester, he does not receive FFWS funds in that semester but remains eligible to receive FFWS funds in future semesters, as long as he continues to meet eligibility requirements.

\section{Contributions to the Literature}

Most financial aid programs do not randomly assign students to aid, which greatly complicates the identification of causal effects of financial aid on college students' success (Dynarski \& Scott-Clayton, 2013). In the existing literature, researchers attempt to surmount the 
non-random selection problem with quasi-experimental techniques, typically using regression discontinuity designs comparing students just above or below a specified eligibility thresholdusually set by standardized test scores, family income, expected family contribution, or high school grade point averages. Several of these observational studies find positive effects of needbased financial aid on persistence and degree completion (Bettinger, Gurantz, Kawano, Sacerdote, \& Stevens, 2019; Castleman \& Long, 2016; Denning, Marx, \& Turner, 2019). The estimated effect on bachelor's degree completion across these studies is an increase of 3 to 5 percentage points, with the annual aid amounts ranging from approximately $\$ 700$ to $\$ 3,500$ (i.e., a similar range as FFWS grant offers). ${ }^{2}$

There are a small number of experimental studies of need-based aid programs. Only one - an unpublished study of the Nebraska-based Susan Thompson Buffet Foundation (STBF) scholarship program (Angrist, Hudson, \& Pallais, 2016)—examined a need-based aid program other than the FFWS. The STBF scholarship program is similar to the FFWS in that both randomize low-income students to scholarship offers in order to encourage college completion. The two major differences are 1) that the STBF randomizes eligible applicants at the end of high school, while the FFWS randomizes eligible students in their first semester of college, and 2) that the FFWS has no application process. The latter difference is potentially important, because prior research has identified application requirements as a major hurdle to receiving aid (Dynarski \& Scott-Clayton, 2006).

Despite these differences, the estimated impacts of the STBF and FFWS need-based grant offers are quite similar. Existing evaluations of both programs find no statistically significant evidence of impacts on persistence into the second year or degree completion for twoyear students (Anderson, Broton, Goldrick-Rab, \& Kelchen, 2018; Anderson \& Goldrick-Rab, 
2018; Angrist et al., 2016). ${ }^{3}$ Studies report that four-year college students in both programs are more likely to persist until their second year, with the STBF study estimating a 6 percentage point increase (Angrist et al., 2016) and an FFWS study estimating a 2.2 percentage point increase in the second and third cohorts—2009-10 and 2010-11 (Goldrick-Rab, Kelchen, Harris, \& Benson, 2016). The major differences in impacts are in degree completion for four-year students. Angrist et al. (2016) find that the STBF offers actually reduced four-year bachelor's degree completion rates by 5.9 percentage points, while Goldrick-Rab et al. (2016) find that the FFWS offers increased bachelor's degree completion rates by 4.7 percentage points in the first cohort (2008-09). To add further uncertainty, there is only a small -0.7 percentage points—and statistically not significant effect on any degree/certificate completion within six years when examining the first four cohorts of four-year FFWS students (Anderson et al., 2018).

Given the consistent inability to reject null effects for two-year students and contradictory estimates of effects on degree completion for four-year students, our goal is to use additional data to further assess the impacts of need-based financial offers in the FFWS. Our study has four advantages in comparison to previous experimental evaluations. First, our study follows up to seven cohorts of FFWS students for up to six years following randomization $(n=48,804)$. The next largest FFWS study_Anderson et al.'s (2018) unpublished report—follows four cohorts of students and has less than half the sample size $(n=20,718)$. Specifically, we use seven cohorts of data for two-year estimates (e.g., persistence), six cohorts of data for three-year estimates (e.g., associate's degree completion and transfers), and five cohorts of data for four-year estimates (e.g., four-year bachelor’s degree completion).

The second advantage is our ability to separately estimate effects for technical college students and community college students. The previous FFWS studies of two-year students 
(Anderson et al., 2018; Anderson \& Goldrick-Rab, 2018) only included the first cohort of technical college students and did not explore differences in effectiveness by college type. It is possible that the null effects estimated in past studies may be masking heterogeneous effects between community college and technical college students.

Our measures of degree completion are a third advantage. The most recent FFWS evaluations (Anderson et al., 2018; Anderson \& Goldrick-Rab, 2018) assess combined impacts on any type of certificate or degree completion. Distinguishing between degree types may be important, especially for two-year students. Among students who began at two-year schools, the STBR study found a negative relationship between the grant offer and associate's degree completion, and a positive relationship between the grant offer and bachelor's degree completions (Angrist et al., 2016). Neither relationship is statistically significant, but the results suggest that need-based financial aid offers may increase bachelor's degree completion among two-year college students at the cost of associate's degree completion. In this paper, we estimate separate impacts on associate's degree completions and bachelor's degree completions.

Finally, our analysis evaluates not only the effects of the grant offer, but also the effects of grant aid receipt, which have not yet been studied in an FFWS evaluation of degree completion and persistence. Because a sizeable portion of the treatment group does not receive grant funds, the effects of receiving grant funds necessarily differ from the effects of receiving an offer.

\section{Data \& Methods}

Data collection and matching

The data for this evaluation were collected from multiple administrative records sources and matched by the University of Wisconsin Madison's Institute for Research on Poverty (IRP). 
HEAB provided the list of all students (names, birth dates, and Social Security numbers) who were eligible to be randomized to the grant, as well as indicators of randomized control or treatment group membership. IRP linked the records of eligible students to three main data sources: the University of Wisconsin System (UWS) enrollment records, the Multi-Sample Person File (MSPF), and the Department of Public Instruction database.

IRP used Social Security numbers to link eligible students to UWS and MSPF data. The UWS records provide enrollment dates, credit completion, Pell Grant amounts, and other records for students enrolled in UWS two- and four-year schools. Note that these records do not include Wisconsin Technical College System (WTCS) students, which limits our ability to use these data for our main analyses. The MSPF is a list of names and anonymized IDs compiled by IRP that includes Wisconsin residents who are found in one of seven administrative databases. One of these databases is the Client Assistance for Re-Employment and Economic Support (CARES) system, which contains means-tested benefits receipt records (e.g., Supplementary Nutrition Assistance Program, Temporary Assistance for Needy Families, etc.) linked to household heads and children in their households. Because MSPF records are linked to all Wisconsin residents who have entered one of the seven contributing administrative databases, students from both the UWS (two- and four-year schools) and WTCS are matched to these records.

The Department of Public Instruction (DPI) records include background information on K-12 school achievement (we use data from the last recorded enrollment), demographics (e.g., race, gender, English language abilities), and post-secondary outcomes data on college enrollments and degree completions as reported by the National Student Clearinghouse (NSC), which are purchased annually by DPI. IRP matched the FFWS student records to the DPI data using two methods. The first method exactly matched FFWS student records to DPI records 
using students' names and birth dates and then "fuzzily” matched on names and birth dates for the remaining unmatched cases_-around 4 percent of cases. ${ }^{4}$ The second method matched FFWS student records indirectly to DPI data by first matching to the MSPF by social security number and then using a pre-existing, annually-updated comprehensive match between the MSPF and DPI data. IRP combined these two methods to increase the overall match rate. The DPI records include information on any student who attended a public Wisconsin school, so both UWS (twoand four-year) and WTCS students were matched to baseline and outcomes data found in the DPI database.

We have near-complete matches between the full sample of 48,804 unique students eligible to be randomized to receive an FFWS grant offer from the 2009-10 through 2015-16 cohorts and the UWS data (99.9 percent), the MSPF data (100 percent), and the DPI/NSC data (98.7 percent). Although only 86.7 percent of eligible students were found in the MSPF, a student will only appear in the MSPF if he or she (or their household head) ever received meanstested benefits in Wisconsin. We are treating an absence of records in the MSPF as indicating no receipt of means-tested benefits, which accounts for the 100 percent match rate.

Because some of the matching between the FFWS student sample and the DPI/NSC data relied on names and birthdates, a small portion (2.5 percent) of students in the FFWS student sample were matched to multiple records in the DPI/NSC data with similar names and birthdates. To address these multiple matches in our analysis, we randomly select one of the matched DPI/NSC records. We also re-estimate each of our analyses by dropping all cases matched to multiple DPI/NSC records to ensure robustness. (Results did not appreciably change; available upon request.)

Analytic dataset 
HEAB provided us with 48,804 unique students from the 2009-10 through 2015-16 cohorts entered into the population of FFWS-eligible students. Approximately 2 percent of these students appear in the data more than once due to administrative errors in the randomization process. Although students were only supposed to be eligible for randomization in their first post-secondary enrollment, 2.01 percent of students were entered into the randomization pool twice, and less than 0.1 percent were randomized three times. Discussions with the FFWS governing board indicated that these erroneous re-randomizations could have occurred when students transferred to a new school that either did not possess students' previous enrollment records or neglected to remove these ineligible students from the eligibility pool. ${ }^{5}$

The manner in which the FFWS dealt with these erroneous re-randomizations depended on the previous randomization of the student. Since the FFWS does not know which students were randomized to control, a control student who was re-randomized from control to treatment would be offered a grant if administrators did not detect her ineligibility in the final postrandomization screening process. However, if a student had previously been randomized to treatment, their previous grant arrangement would remain in place regardless of whether the new randomization resulted in a control or treatment assignment as long as he or she continued to meet the eligibility criteria. ${ }^{6}$ To preserve the experimental design, we treat each student's randomization as a unique observation, yielding 49,807 observations in our analytic dataset. ${ }^{7}$ The number of observations varies across analyses, as shown in the results tables and Appendix 1 Table A3. For example, the analysis of six-year bachelor's degree completion models uses three cohorts of data, while the analysis of two-year persistence uses seven cohorts of data.

\section{Measures}


The primary treatment variable in this paper is the indicator of being randomized to receive an FFWS grant offer, coded as “1” for students randomized to receive an offer and coded as "0” for students randomized not to receive an offer. As mentioned above, the FFWS made around 550 to 650 offers each year to students in each of the two- and four-year student samples. These students serve as the treatment group for each cohort, with the remainder of the eligible sample serving as the control group. This variable is used for our intent-to-treat (ITT) estimates of the effect of an FFWS grant offer on student outcomes. However, not all FFWS offer recipients actually received FFWS grant funds for the reasons discussed above (e.g., failing to accept the offer). In order to estimate the effect of actually receiving grant aid on student outcomes, we conduct a treatment-on-the-treated (TOT) analysis using an instrumental-variables approach. Students who received any FFWS funds in their first semester according to UWS records are coded as “ 1 ” while the others are coded as “ 0. . (Very few students who do not receive aid in the first semester receive aid at a later time; see Appendix 2 Table A4.).

The primary outcomes of interest for all students (regardless of initial enrollment in twoor four-year institutions) are persistence into the second academic year (i.e., third academic semester) and six-year bachelor’s degree completion. We measure two-year persistence as having an NSC enrollment record in each of the two semesters following the fall semester of randomization (i.e. January-March of the first academic year and August-October of the next academic year). ${ }^{8}$ We measure six-year bachelor's degree completion as having a completed bachelor's degree in the NSC data during or prior to the sixth summer following initial randomization.

Secondary outcomes include three-year associate’s degree completion (for the two-year student sample) and four-year bachelor's degree completion (for the four-year student sample), 
which we measure using the same coding scheme based on the NSC data. We also explore whether two-year beginners who receive a grant offer are more likely to transfer to a four-year college within three years of initial enrollment. We code a two-year student as a transfer if he or she has an NSC enrollment in a four-year college by the third August following initial randomization. To better measure transfers (as opposed to enrollments for single classes or summer classes), we only classify an enrollment as a transfer if it indicated full-time student status from January to March or August to October. These latter requirements were not preregistered, but are necessary to differentiate transfers from other types of enrollments.

We model two- and four-year college enrollees separately and include fixed effects for randomization cohort to account for blocked randomization by school type and cohort. We control for race, gender, English language learner (ELL) status, and Supplementary Nutrition Assistance Program (SNAP) receipt to increase statistical efficiency. We measure race, gender, and ELL status using a student's last recorded high school enrollment year in the DPI data. DPI records gender as "Male” or "Female” (baseline category). DPI also records seven levels of ELL abilities, with 7 indicating a student was never classified as an ELL and 1-6 indicating different levels of English language proficiency. We code this measure into the binary categories of “Never ELL” (baseline) and “Ever ELL.” Finally, DPI records seven racial categories, which we recode into three categories: “White” (baseline), “Underrepresented” (African American, Hispanic, Native American, and Pacific Islander-latter not present in our data), and “Asian.” 9 We coded a student as receiving SNAP if he or she had any recorded household SNAP receipt in the CARES database in the two calendar years prior to initial enrollment. Otherwise, we code a student as receiving no SNAP funds (baseline). ${ }^{10} 36$ percent of two-year students and 
25 percent of four-year students were members of households that received SNAP in the two years prior to randomization.

Finally, the technical college indicator is a binary measure of whether a student was randomized at a technical college (i.e., in the Wisconsin Technical College System). We only use this measure in the two-year college student models.

Analytic strategy

We estimate the causal ITT effect of receiving an FFWS grant offer on each outcome using a linear probability model, which we estimate via ordinary least squares (OLS) separately for two- and four-year enrollees:

$$
Y_{i j}=\beta+\delta T_{i j}+\gamma \boldsymbol{X}_{i j}+C_{j}+\varepsilon_{i}
$$

where $Y_{i j}$ represents the outcome of interest (e.g., two-year persistence, six-year bachelor's degree completion, etc.) for student $i$ in cohort $j$; $T_{i j}$ represents a student's treatment status; $C_{j}$ is a cohort fixed effect to account for the blocked randomization; and $\boldsymbol{X}_{\boldsymbol{i} \boldsymbol{j}}$ represents a vector of student-level covariates to increase the efficiency of our models (race, gender, English language learner status, receipt of SNAP funds prior to college enrollment, and—-for the models of twoyear college beginners only—a technical college indicator). We compute Huber-White HC3 heteroscedasticity-robust standard errors to account for the inevitable heteroscedasticity in linear probability models (Gordon, 2010). Because randomization occurred at the individual level, we do not cluster standard errors (Abadie, Athey, Imbens, \& Wooldridge, 2017).

Additionally, we explore the causal effects of actually receiving FFWS aid. The effects of grant receipt may differ from the effects of receiving a grant offer since 16.0 percent (2009-15 four-year sample) to 26.5 percent (2009-15 two-year UWS sample) of students who were offered FFWS did not receive any FFWS aid in their first semester of enrollment. (The two-year student 
sample for the TOT analysis only uses UWS and not WTCS students due to data limitations.) The main reasons for not receiving aid among students who were offered aid were students' failure to accept the grant offer, ineligibility due to insufficient unmet need, part-time student status, or a failure to meet initial eligibility criteria (e.g., graduating from a private high school). According to FFWS administrators, the latter reason is quite rare-approximately 35-40 cases per year-and occurred only when an ineligible student was mistakenly entered into the randomization pool. ${ }^{11}$ Additional reasons include that the student may have dropped out or transferred out of the system before receiving aid.

Since aid receipt was not itself randomized, we use the randomization of the grant offer as an instrumental variable (IV) to identify the causal effect of aid receipt in the first semester. We assume that it meets the usual two IV conditions for IV identification: Randomization strongly affects aid receipt ("relevance”), and randomization is plausibly associated with student outcomes only via the effect of aid receipt (“exclusion”). We present a sensitivity analysis for possible exclusion violations in Appendix 2. Since "non-compliance" with the randomized offer of aid receipt is one-sided-FFWS aid is unavailable to students who were not offered to receive it - the IV estimator identifies the effect of aid receipt on those who receive aid (effect of treatment on the treated, TOT).

One minor complication of our TOT analysis is that conventional two-stage least squares IV estimation identifies a weighted average of the individual-level effects if the analysis contains covariates. Because we are interested in the unweighted effect of aid receipt on students who receive aid, and because we control for cohort to account for blocked randomization, we employ the IV estimator of Frölich and Melly (2013, p. 9), which produces an unweighted TOT estimate. $^{12}$ 


\section{Findings}

Balance and attrition

Table 2 presents mean pre-treatment characteristics of our treatment and control groups for two- and four-year college students. While there are slight discrepancies between groups on gender that reach statistical significance among four-year students, we adjust for this difference in our statistical models. Data are missing for only about 3 percent of cases, with no evidence of differential missingness between the treatment and control groups. Therefore, we follow the advice of the What Works Clearinghouse and take no further action to address attrition in our analysis (U.S. Department of Education, 2017).

[Insert Table 2 here]

Main effects of the FFWS grant offer on primary and secondary outcomes (intent to treat)

Table 3 presents estimates for the ITT effects of the FFWS grant offer on the primary and secondary outcomes. We estimate that the FFWS offer increases persistence into the second academic year by 1.2 percentage points for students initially enrolled in two-year colleges (95\% CI: [-0.37, 2.77], $\mathrm{p}=0.138$ ) and 1.7 percentage points for students initially enrolled in four-year universities (95\% CI: [0.33, 3.07], p=0.011). Only the estimate for students who initially enrolled in four-year colleges is statistically significant. The estimated effect on six-year bachelor's degree completion is of a similar magnitude for four-year beginners (1.5 percentage points; 95\% CI: $[-1.05,4.05], p=0.254)$, but this estimate is not statistically significant. For two-year beginners, the estimated causal effect on six-year bachelor's degree attainment is very close to zero (0.5 percentage points; 95\% CI: [-1.07, 2.07], $\mathrm{p}=0.545)$. Considered together, we find evidence that the FFWS grant offer slightly increases college persistence for four-year beginners, but only statistically insignificant evidence that the grant offer increases bachelor's degree 
completion for any students in the long term. ${ }^{13}$ We obtain very similar results in robustness checks using UW Systems enrollment/graduation data instead of the National Student Clearinghouse data (Appendix 1 Table A2).

\section{[Insert Table 3 here]}

We find no statistically significant effects of the FFWS grant offer on secondary outcomes. For three-year associate's degree completion (two-year beginners), transferring to a four-year college within three-years (two-year beginners), and four-year bachelor’s degree completion (four-year beginners), the estimated treatment effects are almost exactly zero and not statistically significant (Table 3). Most of the results are similar when using the UWS data (Appendix 1 Table A2). The only exception is a negative, but not statistically significant, effect on associate's degree completion for UWS (i.e., not technical college) two-year students (-2.2 percentage points; 95\% CI: [-4.94, 0.54]; $\mathrm{p}=0.11$ ). We examine this subgroup-specific effect further below.

Testing for heterogeneities in the effect of the FFWS grant offer

Although we find no statistically significant evidence that the FFWS grant has any effect on six-year bachelor's degree completion on average, it is possible that these estimates mask meaningful effect heterogeneity across groups. To explore variation in the treatment effects on the main outcomes, we re-estimated the models described above, now including an interaction between the treatment variable and one of the characteristics of interest: cohort, race, gender, SNAP receipt, and technical-college status (we did not pre-register testing for heterogeneity by the latter two variables).

Tables 4 and 5 show the subgroup-specific treatment effects on persistence and bachelor's degree completion. In terms of persistence (Table 4), we find some fluctuations in 
estimated treatment effects across cohorts. The impact on persistence for four-year students appears to be driven primarily by the 2013-14 cohort. In this year, receiving an FFWS offer was associated with a 4-percentage point increase in persistence (95\% CI: [0.96, 7.24]; p=0.01). However, the differences in effects between years are relatively minor and not statistically significant (based on the F-test) for either two- or four-year beginners.

With regard to race and gender, the effect of the FFWS offer on two-year persistence among four-year beginners appears to be driven by the effect on white students (2.1 percentage points, 95\% CI: [0.73, 3.47]; $\mathrm{p}=0.005)$ and male students (2.1 percentage points, 95\% CI: [0.02, 4.27]; $\mathrm{p}=0.048)$. However, differences in the effects of the FFWS offer across racial and gender groups are minor and not statistically significant for two-year or four-year beginners based on the F-tests. There are also no statistically significant differences in persistence effects for students who received SNAP in the two-years prior to college or technical college students.

[Insert Table 4 here]

For two-year beginners, Table 5 presents some evidence that the treatment effects on bachelor's degree completion for the 2010-11 cohort and 2011-12 cohort are each different from the treatment effect of the 2009-10 cohort ( $<<0.05$ in both cases). The estimated treatment effect for the 2009-10 cohort is a 2.4 percentage point reduction in six-year bachelor's degree completion rates (95\% CI: [-5.14, 0.34]), compared to an approximately 1.7 percentage point increase for the two later cohorts (95\% CIs: [-1.14, 4.34] and [-0.94, 4.54]). However, none of the cohort-specific treatment-effect estimates are statistically significant, and the F-test does not provide statistically significant evidence that the effect varies across cohorts. For four-year beginners, the effects are consistent with an upward trend over time, but there are no statistically significant cohort-specific effects on six-year bachelor's degree completion within any of the 
three cohorts considered, and we find no statistically significant evidence of treatment effect differences by cohort.

[Insert Table 5 here]

Among two-year beginners, we also find no differences in effects on bachelor's degree completion by race, gender, prior SNAP receipt, or technical college status. The subgroupspecific treatment effects are all close to zero and not statistically significant, and we find no evidence that these effects differ from one another based on the F-tests. The same conclusion holds for four-year beginners. While there is some indication that treatment effects are smaller for Asian students and larger for males, neither the differences between groups nor the subgroupspecific intent-to-treat effects of the grant offer are statistically significant.

Because past research on the FFWS two-year student population was unable to examine more than a single cohort of technical college students (Anderson et al., 2018; Anderson \& Goldrick-Rab, 2018), we also investigated whether effects on three-year associate’s degree completion and transfer differed between technical college students and UWS two-year students. These analyses are exploratory as they were not pre-registered. We find the FFWS offer reduced three-year associate's degree completion by 2.8 percentage points for UWS two-year students (95\% CI: [-5.5, -0.06]; $\mathrm{p}=0.039$ ) and no strong evidence of an effect on technical college students ( 0.8 percentage points; $95 \%$ CI [-0.6, 2.2]; $\mathrm{p}=0.234$ ). The difference in effect sizes is statistically significant (3.6 percentage points; 95\% CI [0.7, 6.5]; p=0.017). Although differential college transfer rates are a possible explanation, we find no strong evidence that effects on transfer vary between groups ( $\mathrm{p}=0.35$ ). In addition, the two-year UWS student subsample is well balanced ( $\mathrm{p}=0.90)$ with no strong evidence that the treatment and control groups differ on any of the six demographic variables we test (see Table 2 for the list of characteristics). 
Effects of FFWS aid receipt on primary outcomes (treatment on the treated)

We next present the estimated TOT effects on our primary outcomes-two-year persistence and six-year bachelor's degree completion. The estimated TOT effects of receiving any grant funds in the first semester on persistence into the second year (Table 6) are slightly larger than the ITT impacts—-2.0 versus 1.2 percentage points for two-year beginners and 2.2 versus 1.7 percentage points for four-year beginners. As in the ITT analysis, only the TOT estimate of two-year persistence among four-year beginners is statistically significant (two-year beginners 95\% CI: [-1.9, 5.9], $\mathrm{p}=0.323$; four-year beginners 95\% CI: [0.6, 3.7], $\mathrm{p}=0.007)$.

The TOT impact on four-year students' bachelor's degree completion is also (mechanically) larger than the ITT impact, suggesting that the graduation rates of students who receive FFWS funds in the first semester are around 2.5 percentage points higher than nonrecipients (95\% CI: $[-0.7,5.6] ; \mathrm{p}=0.128)$. On the other hand, the TOT estimate of bachelor's degree completion for two-year students is still almost zero (0.3 percentage points; 95\% CI: [5.5, 6.1]; $\mathrm{p}=0.919)$. Neither TOT effect on bachelor's degree completion reaches statistical significance at the pre-specified 0.05 level, thereby implying the absence of statistically significant evidence that receiving any FFWS funds in the first semester improves six-year bachelor's degree completion rates.

\section{[Insert Table 6 here]}

The consistency of these TOT estimates depends on two assumptions: randomization meaningfully affects aid receipt ("relevance"), and randomization is associated with student outcomes only via the effect of aid receipt (“exclusion”). The relevance assumption is satisfied in our data. A regression of aid receipt in the first semester on treatment status among the 2009-15 cohorts reveals a strong relationship for both the two-year UWS samples $(F=11,225, p<0.001)$ 
and four-year samples $(\mathrm{F}=102,756, \mathrm{p}<0.001)$, since the majority of treated students — and none of the control students-receive first-semester aid (see Table A4 in Appendix 2). However, the exclusion assumption is potentially violated if randomization directly affects student outcomes through the receipt of a grant offer, even if an offer recipient never received any FFWS aid. Appendix 2 develops an argument that our TOT estimates may be upwardly biased if students who received and accepted a grant offer were more likely to persist because they felt more financially secure (even if they did not receive money in the first semester). Appendix 2 also suggests, however, that, regardless of its direction, the absolute size of the bias is likely small.

\section{Conclusions}

Because of non-random selection, it is generally difficult to assess the impact of financial aid on educational outcomes. The FFWS scholarship program removes this difficulty by assigning grant offers at random within a pool of eligible students who are already enrolled. This paper estimates the causal effect of being offered an FFWS grant on college persistence and college completion for all available cohorts of the FFWS other than the inception cohort (not present in our data), using a pre-registered analysis plan. Following students for up to six years after college entry, our results suggest that recipients of grant offers at four-year institutions persist into their second academic year at higher rates (1.7 percentage point increase). The positive effect on persistence for four-year students is similar to the effect found for the inception cohort of the FFWS (Goldrick-Rab et al., 2016), suggesting the effect persists in later cohorts and is robust to using national—as opposed to within-system—data. Like the previous evaluations of two-year students (Anderson et al., 2018; Anderson \& Goldrick-Rab, 2018), we fail to find statistically significant impacts on college persistence while using additional cohorts (seven versus three and four cohorts, respectively), multiple cohorts of technical college 
students, and tracking students both within and outside of the public Wisconsin college systems. Unlike the past studies of two-year students, we separately assess specific impacts on associate’s and bachelor's degree completion. We find no statistically significant effects on associate’s degree completion over three years or bachelor's degree completion over six years, even when including degree completions outside of the public Wisconsin college systems. It is also noteworthy that the effect sizes we estimate tend to be smaller than the previous observational studies of financial aid, many of which use regression discontinuity designs. The discrepancy in effect sizes may be due to the fact that regression discontinuity designs estimate effects for the limited group of students on either side of a discontinuity (e.g., students with financial need immediately above and below the cutoff in a grant formula).

The largest discrepancy between our findings and prior FFWS evaluations is our failure to find an effect on bachelor's degree completions among four-year college students. Using data from the first FFWS cohort (2008), Goldrick-Rab et al. (2016) report a statistically significant 4.7 percentage point increase in four-year bachelor's degree completion among FFWS offer recipients at four-year colleges. Using the next five FFWS cohorts (2009-2013), we find no statistically significant evidence of impacts on four-year bachelor's degree completion, nor do we find statistically significant evidence of impacts on six-year bachelor's degree completion using the next three FFWS cohorts (2009-2011), although our point estimates are consistently positive. These results hold regardless of whether we use national NSC data or within-system UWS data (see Appendix 1 Table A2). Since we do not have access to the 2008 cohort's data, we cannot account for this difference between Goldrick-Rab et al.'s (2016) results and our own. However, Goldrick-Rab et al. (2016, p. 1803) report that some financial aid officers may have improperly administered the program during the first cohort. The recent unpublished assessment 
of the first four FFWS cohorts (Anderson et al., 2018) provides additional information. They find that an impact on any degree/certificate completion in the 2008 cohort of four-year students disappears by the fifth year after randomization, with the control group actually completing degrees/certificates at higher rates by the seventh year (p. 25). Anderson et al. (2018) similarly find no statistically significant impact on any degree or certificate completion within five years when pooling the 2008-2011 cohorts of four-year students.

Although we find no statistically significant evidence of impacts on bachelor's degree completions, our exploratory analysis of heterogeneous effects in three-year associate's degree completion suggests that the FFWS grant offer was detrimental to two-year UWS students. FFWS students within this population completed associate’s degrees at lower rates (a 2.8 percentage point reduction). In comparison, we found no statistically significant evidence of (positive or negative) effects on technical college students. The effect on two-year UWS students is similar using UWS data (see Appendix 1 Table A2), but does not reach statistical significance. In the previous FFWS study of two-year students (Anderson et al., 2018; Anderson \& GoldrickRab, 2018), the authors report that the grant offer reduced any degree/certificate completion rates by around 1 percentage point, but these effects were not statistically significant. The STBF study (Angrist et al., 2016) reports a larger-but still not statistically significant—reduction of 12 percentage points in associate’s degree completions for two-year students. Angrist et al. (2016) suggest that financial aid offers could push students away from associate's degrees and towards bachelor's degrees. However, we find no differential effects on four-year college transfer or bachelor’s degree completion between UWS and technical college students.

At least four mechanisms may explain why FFWS grant offers do not appear to increase degree completion. First, in addition to simply offering more money, it is possible that the FFWS 
offer's effectiveness would be greater if coupled with other student support services. For example, previous research suggests that financial aid incentives combined with mentoring and academic support programs are effective in improving academic performance (Angrist, Lang, \& Oreopoulos, 2009), but additional mentoring services were not part of the FFWS cohorts evaluated in this study. Some FFWS-eligible campuses began to offer these supports in the 201617 school year, so it is possible that future evaluations will find larger effects over time as data become available for more recent cohorts.

Second, it is possible that the grant is not effective for the target population or investigated subpopulations, but is effective for yet-to-be discovered subgroups of students. In this paper, we analyzed five potential sources of heterogeneous effects: cohort, race, gender, receipt of SNAP, and attending a technical college versus a community college. We find some indications that FFWS grant effectiveness is concentrated among male, white, four-year college students, and that effectiveness has increased over time. However, none of these differences is statistically significant. Future studies should further explore of heterogeneous treatment effects of the FFWS program.

Third, the program's effectiveness could be limited if many students either 1) fail to accept the initial grant offer or 2) do not receive grant funds after accepting the offer (for the reasons discussed above). Although we do not have access to data measuring grant acceptance, we show that 16 percent of four-year students and 26.5 percent of two-year students do not receive FFWS grant funds in their first semester, suggesting the issue of take-up is potentially important. We investigated this issue using a treatment-on-the-treated analysis that allowed us to estimate impacts on students who received grant funds in the semester of randomization. Our 
estimated TOT impacts are slightly larger, but again only provide statistically significant evidence of effects on persistence and not on bachelor's degree completion.

Fourth, the sample size for estimating six-year effects is relatively small (see Table A3 in Appendix 1). The estimated effect on six-year bachelor's degree completion for four-year students (1.5 percentage points) is only slightly smaller than the statistically significant estimated effect on two-year persistence (1.7 percentage points). We use seven cohorts of data to estimate the effect on persistence compared to only three cohorts of data for bachelor's degree completion, which yields increased power for detecting effects of this size. The minimum detectable effect size (5 percent level with 80 percent power) for persistence is 2.0 percentage points, compared to 3.6 percentage points for six-year bachelor's degree completion.

In sum, we find evidence that FFWS grant offers lead to small increases in persistence for four-year college students, allowing these students to make the often challenging transition between freshman and sophomore year. The effect on six-year bachelor's degree completion for four-year students is of a similar magnitude (in percentage point terms), but not statistically significant. Future work should further explore whether FFWS grant offers could be more effective if targeted at specific subgroups of students, and also use additional cohorts of data to re-estimate effects on persistence and degree completion with greater precision. 


\section{References}

Abadie, A., Athey, S., Imbens, G., \& Wooldridge, J. (2017). When should you adjust standard errors for clustering? National Bureau of Economic Research Working Paper (24003). Retrieved from https://www.nber.org/papers/w24003

Anderson, D. M., Broton, K. M., Goldrick-Rab, S., \& Kelchen, R. (2018). Experimental Evidence on the Impacts of Need-Based Financial Aid: Longitudinal Assessment of the Wisconsin Scholars Grant. The Hope Center. Retrieved from https://hope4college.com/wpcontent/uploads/2018/09/Anderson_et_al_2018_Experimental-Evidence-on-the-Impactsof-Need-Based-Financial-Aid_Longitudinal-Assessment-of-the-Wisconsin-ScholarsGrant.pdf

Anderson, D. M., \& Goldrick-Rab, S. (2018). Aid after enrollment: Impacts of a statewide grant program at public two-year colleges. Economics of Education Review, 67, 148-157.

Angrist, J., Hudson, S., \& Pallais, A. (2016). Evaluating post-secondary aid: Enrollment, persistence, and projected completion effects. National Bureau of Economic Research Working Paper (23015). Retrieved from https://www.nber.org/papers/w23015

Angrist, J., Lang, D., \& Oreopoulos, P. (2009). Incentives and services for college achievement: Evidence from a randomized trial. American Economic Journal: Applied Economics, 1(1), 136-163.

Bailey, M. J., \& Dynarski, S. (2011). Inequality in Postsecondary Education. In G. J. Duncan \& R. J. Murnane (Eds.), Whither Opportunity? Rising Inequality, Schools, and Children's Life Chances. New York, NY: Russell Sage.

Baum, S., Ma, J., Pender, M., \& Bell, D. W. (2015). Trends in Student Aid 2015. Trends in Higher Education. College Board. Retrieved from https://files.eric.ed.gov/fulltext/ED572541.pdf

Bettinger, E., Gurantz, O., Kawano, L., Sacerdote, B., \& Stevens, M. (2019). The Long-Run Impacts of Financial Aid: Evidence from California's Cal Grant. American Economic Journal: Economic Policy, 11(1), 64-94.

Castleman, B. L., \& Long, B. T. (2016). Looking beyond enrollment: The causal effect of needbased grants on college access, persistence, and graduation. Journal of Labor Economics, 34(4), 1023-1073.

Denning, J. T., Marx, B. M., \& Turner, L. J. (2019). ProPelled: The effects of grants on graduation, earnings, and welfare. American Economic Journal: Applied Economics, 11(3), 193-224.

Dynarski, S., \& Scott-Clayton, J. (2006). The Cost Of Complexity In Federal Student Aid: Lessons From Optimal Tax Theory And Behavioral Economics. National Tax Journal, 59(2), 319-356. 
Dynarski, S., \& Scott-Clayton, J. (2013). Financial aid policy: Lessons from research. The Future of Children, 23(1), 67-91.

Frölich, M., \& Melly, B. (2013). Identification of Treatment Effects on the Treated with OneSided Non-Compliance. Econometric Reviews, 32(3), 384-414.

Goldrick-Rab, S., Kelchen, R., Harris, D. N., \& Benson, J. (2016). Reducing income inequality in educational attainment: Experimental evidence on the impact of financial aid on college completion. American Journal of Sociology, 121(6), 1762-1817.

Gordon, R. A. (2010). Regression analysis for the social sciences: Routledge.

Heckman, J., Smith, J., \& Taber, C. (1998). Accounting for dropouts in evaluations of social programs. Review of Economics and Statistics, 80(1), 1-14.

Leonhardt, D., \& Chinoy, S. (2019, May 23). The College Dropout Crisis. The New York Times. Retrieved from https://nyti.ms/2HN8FSv

Lin, W. (2013). Agnostic notes on regression adjustments to experimental data: Reexamining Freedman’s critique. The Annals of Applied Statistics, 7(1), 295-318.

Ma, J., Baum, S., Pender, M., \& Libassi, C. (2018). Trends in College Pricing, 2018. Trends in Higher Education Series. College Board. Retrieved from https://trends.collegeboard.org/sites/default/files/2018-trends-in-college-pricing.pdf

U.S. Department of Education. (2017). What Works Clearinghouse Standards Handbook, Version 4.0. What Works Clearinghouse. Washington, D.C. Retrieved from https://ies.ed.gov/ncee/wwc/Docs/referenceresources/wwc_standards_handbook_v4.pdf 
Tables

Table 1:

Enrollment, Pell Grants, and Tuition at Wisconsin Public Colleges and Universities, 2016-17

\begin{tabular}{|c|c|c|c|c|c|}
\hline & $\begin{array}{l}\text { Undergraduate } \\
\text { enrollment }\end{array}$ & $\begin{array}{l}\text { Pell } \\
\text { recipients }\end{array}$ & $\begin{array}{l}\text { Percent } \\
\text { Pell }\end{array}$ & $\begin{array}{l}\text { Average } \\
\text { Pell }\end{array}$ & $\begin{array}{l}\text { Tuition } \\
\text { and fees }\end{array}$ \\
\hline & \multicolumn{5}{|c|}{$\begin{array}{c}\text { Two-year colleges: Wisconsin Technical College System } \\
\text { and the University of Wisconsin Colleges }\end{array}$} \\
\hline Blackhawk & 2,034 & 1,275 & $63 \%$ & $\$ 3,029$ & $\$ 4,107$ \\
\hline Chippewa Valley & 6,640 & 1,959 & $30 \%$ & $\$ 3,315$ & $\$ 4,238$ \\
\hline Fox Valley & 11,759 & 2,146 & $18 \%$ & $\$ 3,340$ & $\$ 4,436$ \\
\hline Gateway & 8,722 & 2,591 & $30 \%$ & $\$ 3,288$ & $\$ 4,152$ \\
\hline Lakeshore & 2,640 & 826 & $31 \%$ & $\$ 4,367$ & $\$ 4,125$ \\
\hline Madison Area & 15,638 & 3,809 & $24 \%$ & $\$ 3,213$ & $\$ 4,281$ \\
\hline Mid-State & 2,764 & 1,164 & $42 \%$ & $\$ 3,497$ & $\$ 4,321$ \\
\hline Milwaukee Area & 15,057 & 6,914 & $46 \%$ & $\$ 3,258$ & $\$ 4,426$ \\
\hline Moraine Park & 6,041 & 1,135 & $19 \%$ & $\$ 2,935$ & $\$ 4,340$ \\
\hline Nicolet Area & 1,083 & 475 & $44 \%$ & $\$ 3,557$ & $\$ 4,642$ \\
\hline Northcentral & 4,212 & 1,561 & $37 \%$ & $\$ 3,376$ & $\$ 4,313$ \\
\hline Northeast Wisconsin & 9,742 & 2,819 & $29 \%$ & $\$ 3,305$ & $\$ 4,355$ \\
\hline Southwest Wisconsin & 2,010 & 655 & $33 \%$ & $\$ 3,825$ & $\$ 4,340$ \\
\hline UW Colleges & 11,940 & 2,944 & $25 \%$ & $\$ 3,651$ & $\$ 5,159$ \\
\hline Waukesha County & 7,947 & 1,459 & $18 \%$ & $\$ 3,125$ & $\$ 4,340$ \\
\hline Western & 4,272 & 1,587 & $37 \%$ & $\$ 3,624$ & $\$ 3,776$ \\
\hline \multirow[t]{2}{*}{ Wisconsin Indianhead } & 2,944 & 1,225 & $42 \%$ & $\$ 3,395$ & $\$ 4,598$ \\
\hline & \multicolumn{5}{|c|}{ Four-year universities: University of Wisconsin System } \\
\hline UW-Eau Claire & 10,085 & 2,309 & $23 \%$ & $\$ 3,897$ & $\$ 8,812$ \\
\hline UW-Green Bay & 6,757 & 1,831 & $27 \%$ & $\$ 3,743$ & $\$ 7,878$ \\
\hline UW-La Crosse & 9,751 & 1,967 & $20 \%$ & $\$ 3,879$ & $\$ 9,091$ \\
\hline UW-Madison & 30,958 & 3,891 & $13 \%$ & $\$ 4,078$ & $\$ 10,488$ \\
\hline UW-Milwaukee & 20,968 & 7,194 & $34 \%$ & $\$ 4,093$ & $\$ 9,493$ \\
\hline UW-Oshkosh & 12,484 & 2,757 & $22 \%$ & $\$ 3,932$ & $\$ 7,544$ \\
\hline UW-Parkside & 4,248 & 1,680 & $40 \%$ & $\$ 4,090$ & $\$ 7,367$ \\
\hline UW-Platteville & 7,861 & 1,913 & $24 \%$ & $\$ 3,926$ & $\$ 7,484$ \\
\hline UW-River Falls & 5,494 & 1,552 & $28 \%$ & $\$ 3,925$ & $\$ 7,981$ \\
\hline UW-Stevens Point & 8,297 & 2,683 & $32 \%$ & $\$ 4,041$ & $\$ 8,159$ \\
\hline UW-Stout & 8,412 & 2,207 & $26 \%$ & $\$ 3,857$ & $\$ 9,395$ \\
\hline UW-Superior & 2,367 & 845 & $36 \%$ & $\$ 3,834$ & $\$ 8,088$ \\
\hline UW-Whitewater & 11,409 & 3,000 & $26 \%$ & $\$ 4,008$ & $\$ 7,650$ \\
\hline
\end{tabular}

Source: U.S. Department of Education Integrated Postsecondary Data Education System 


\section{Table 2:}

Pre-treatment covariate balance and attrition due to missing data, 2009-10 through 2015-16 cohorts

\begin{tabular}{lcccccc}
\hline & \multicolumn{3}{c}{ Two-year beginners } & \multicolumn{3}{c}{ Four-year beginners } \\
& Control & Treatment & p-value & Control & Treatment & p-value \\
\hline White (\%) & 78.29 & 77.96 & 0.696 & 76.74 & 76.68 & 0.990 \\
Underrepresented race (\%) & 15.07 & 15.92 & 0.622 & 14.83 & 15.17 & 0.636 \\
Asian (\%) & 6.64 & 6.13 & 0.160 & 8.44 & 8.16 & 0.550 \\
Male (\%) & 47.58 & 49.28 & 0.079 & 43.39 & 40.77 & 0.003 \\
Ever ELL (\%) & 8.07 & 8.15 & 0.592 & 8.59 & 8.88 & 0.632 \\
Received SNAP funds (\%) & 35.56 & 37.78 & 0.163 & 25.35 & 25.27 & 0.475 \\
& & & & & & \\
Total Obs. & 14,644 & 4,618 & & 26,552 & 3,993 & \\
Missing any data (\%) & 2.55 & 2.45 & 0.981 & 2.08 & 2.08 & 0.898 \\
F-test & 1.46 & & 0.199 & 2.27 & & 0.045 \\
\hline
\end{tabular}

Notes: This table uses the sample from the two-year persistence models (2009-10 through 201516 cohorts). The F-tests represent tests of the amount of variation in treatment status accounted for by the four baseline covariates (race, gender, ELL status, and SNAP receipt) in models that regressed the treatment group indicator on all baseline covariates and cohort, using HC3 standard errors. P-values refer to statistical significance (two-tailed t-tests) of individual coefficients, from the same models. 
Table 3:

Estimated intent-to-treat effects of FFWS grant offers on primary and secondary outcomes (percentage point changes)

\begin{tabular}{|c|c|c|c|c|c|c|c|c|c|}
\hline & \multirow[t]{2}{*}{ Cohorts } & \multicolumn{4}{|c|}{ Two-year beginners } & \multicolumn{4}{|c|}{ Four-year beginners } \\
\hline & & $\begin{array}{c}\text { Control } \\
\text { Rate }\end{array}$ & $\begin{array}{l}\text { Treatment } \\
\text { Effect }\end{array}$ & $\begin{array}{c}p- \\
\text { value }\end{array}$ & $N$ & $\begin{array}{c}\text { Control } \\
\text { Rate }\end{array}$ & $\begin{array}{c}\text { Treatment } \\
\text { Effect }\end{array}$ & $\begin{array}{c}p- \\
\text { value }\end{array}$ & $N$ \\
\hline \multicolumn{10}{|l|}{ Primary outcomes } \\
\hline Two-year persistence & $2009-15$ & $50.1 \%$ & $\begin{array}{c}1.20 \\
(0.80)\end{array}$ & 0.138 & 18,775 & $79.5 \%$ & $\begin{array}{c}1.70 \\
(0.70)\end{array}$ & 0.011 & 29,910 \\
\hline Six-year bachelor’s & $2009-11$ & $10.3 \%$ & $\begin{array}{c}0.50 \\
(0.80)\end{array}$ & 0.545 & 8,519 & $53.4 \%$ & $\begin{array}{c}1.50 \\
(1.30)\end{array}$ & 0.254 & 13,660 \\
\hline $\begin{array}{l}\text { Secondary outcomes } \\
\text { Three-year associate's }\end{array}$ & $2009-14$ & $15.1 \%$ & $\begin{array}{l}-0.30 \\
(0.60)\end{array}$ & 0.693 & 16,736 & - & - & - & - \\
\hline $\begin{array}{l}\text { Transfer to four-year } \\
\text { within three years }\end{array}$ & $2009-14$ & $16.7 \%$ & $\begin{array}{c}0.00 \\
(0.70)\end{array}$ & 0.965 & 16,736 & - & - & - & - \\
\hline Four-year bachelor’s & $2009-13$ & - & - & - & - & $21.6 \%$ & $\begin{array}{c}0.00 \\
(0.80) \\
\end{array}$ & 0.998 & 21,929 \\
\hline
\end{tabular}

Notes: Models estimate outcomes using the model described above. Huber-White HC3 adjusted standard errors are shown in parentheses. 
Table 4:

Subgroup-specific ITT effects of FFWS grant offers on two-year persistence rates (percentage point changes) estimated from interacted models (2009-10 through 2015-16 cohorts)

Two-Year Beginners

Four-Year Beginners

\begin{tabular}{|c|c|c|c|c|c|c|}
\hline & Coefficient & S.E. & p-value & Coefficient & S.E. & p-value \\
\hline \multicolumn{7}{|l|}{ By cohort } \\
\hline 2009-10 & -0.70 & 2.40 & 0.784 & 1.20 & 1.80 & 0.512 \\
\hline 2010-11 & 1.00 & 2.20 & 0.656 & 1.60 & 1.80 & 0.376 \\
\hline 2011-12 & 3.50 & 2.20 & 0.103 & 1.20 & 1.70 & 0.461 \\
\hline 2012-13 & -1.80 & 2.20 & 0.410 & -0.50 & 1.70 & 0.765 \\
\hline 2013-14 & 1.70 & 2.10 & 0.429 & 4.10 & 1.60 & 0.012 \\
\hline 2014-15 & 3.10 & 2.20 & 0.153 & 1.90 & 1.80 & 0.293 \\
\hline 2015-16 & 1.60 & 2.30 & 0.485 & 2.40 & 1.90 & 0.200 \\
\hline F-test (of interactions) & 0.76 & & 0.602 & 0.62 & & 0.712 \\
\hline \multicolumn{7}{|l|}{ By race } \\
\hline White & 0.90 & 0.90 & 0.344 & 2.10 & 0.70 & 0.005 \\
\hline Underrepresented & 2.90 & 2.10 & 0.159 & 1.80 & 1.90 & 0.362 \\
\hline $\operatorname{Asian}^{\top}$ & 1.30 & 3.30 & 0.702 & -2.00 & 2.50 & 0.412 \\
\hline F-test (of interactions) & 0.39 & & 0.678 & 1.34 & & 0.262 \\
\hline \multicolumn{7}{|l|}{ By gender } \\
\hline Female & 1.00 & 1.20 & 0.384 & 1.40 & 0.80 & 0.101 \\
\hline Male & 1.50 & 1.20 & 0.217 & 2.10 & 1.10 & 0.048 \\
\hline F-test (of interactions) & 0.08 & & 0.779 & 0.30 & & 0.583 \\
\hline \multicolumn{7}{|l|}{ By SNAP receipt ${ }^{\mathrm{T}}$} \\
\hline Prior (last two years) & 1.90 & 1.40 & 0.157 & 1.60 & 1.50 & 0.263 \\
\hline None prior & 0.80 & 1.10 & 0.433 & 1.70 & 0.70 & 0.021 \\
\hline F-test (of interactions) & 0.42 & & 0.519 & 0.00 & & 0.969 \\
\hline \multicolumn{7}{|l|}{ By technical college $^{T}$} \\
\hline UW System (two-year) & 1.00 & 1.50 & 0.479 & - & - & - \\
\hline Technical college & 1.30 & 1.00 & 0.190 & - & - & - \\
\hline F-test (of interactions) & 0.03 & & 0.874 & - & - & - \\
\hline
\end{tabular}

Notes: We present the estimated treatment effect of FFWS grant offers for each subgroup calculated as the linear combination of the baseline treatment effect and the interaction terms. All models include the same baseline covariates as in Table 3, with equivalent sample sizes. (See Table A3 in Appendix 1 for subgroup sample sizes.) For each model, the F-value tests the improvement in model fit associated with the inclusion of the interaction terms. We provide the Huber-White HC3 standard errors for the subgroup-specific treatment effects. ${ }^{\mathrm{T}}$ Indicates that this heterogeneous variable/subgroup was not pre-registered and is exploratory. 
Table 5:

Subgroup-specific ITT effects of FFWS grant offers on six-year bachelor's degree completion rates (percentage point changes) estimated from interacted models (2009-10 through 2011-12 cohorts)

\begin{tabular}{|c|c|c|c|c|c|c|}
\hline & \multicolumn{3}{|c|}{ Two-Year Beginners } & \multicolumn{3}{|c|}{ Four-Year Beginners } \\
\hline & Coefficient & S.E. & p-value & Coefficient & S.E. & p-value \\
\hline \multicolumn{7}{|l|}{ By cohort } \\
\hline 2009-10 & -2.40 & 1.40 & 0.076 & 0.60 & 2.30 & 0.788 \\
\hline 2010-11 & 1.60 & 1.40 & 0.236 & 0.80 & 2.30 & 0.732 \\
\hline 2011-12 & 1.80 & 1.40 & 0.181 & 2.80 & 2.10 & 0.189 \\
\hline F-test (of interactions) & 2.93 & & 0.054 & 0.31 & & 0.734 \\
\hline \multicolumn{7}{|l|}{ By race } \\
\hline White & 0.50 & 0.90 & 0.548 & 1.80 & 1.40 & 0.221 \\
\hline Underrepresented & -0.30 & 1.70 & 0.872 & 1.60 & 3.50 & 0.651 \\
\hline $\operatorname{Asian}^{\Phi}$ & 1.20 & 3.30 & 0.719 & -1.80 & 4.70 & 0.703 \\
\hline F-test (of interactions) & 0.08 & & 0.921 & 0.27 & & 0.760 \\
\hline \multicolumn{7}{|l|}{ By gender } \\
\hline Female & -0.30 & 1.20 & 0.775 & 0.30 & 1.70 & 0.868 \\
\hline Male & 1.30 & 1.10 & 0.213 & 3.10 & 2.00 & 0.120 \\
\hline F-test (of interactions) & 1.13 & & 0.289 & 1.19 & & 0.275 \\
\hline \multicolumn{7}{|l|}{ By SNAP receipt ${ }^{\mathrm{T}}$} \\
\hline Prior (last two years) & 0.10 & 1.20 & 0.958 & 1.70 & 3.00 & 0.565 \\
\hline None prior & 0.70 & 1.00 & 0.515 & 1.40 & 1.40 & 0.322 \\
\hline F-test (of interactions) & 0.12 & & 0.730 & 0.01 & & 0.925 \\
\hline \multicolumn{7}{|l|}{ By technical college $^{T}$} \\
\hline UW System (two-year) & 0.10 & 2.20 & 0.947 & - & - & - \\
\hline Technical college & 0.60 & 0.70 & 0.406 & - & - & - \\
\hline F-test (of interactions) & 0.07 & & 0.796 & - & - & - \\
\hline
\end{tabular}

Notes: We present the estimated treatment effect of FFWS grant offers for each subgroup calculated as the linear combination of the baseline treatment effect and the interaction terms. All models include the same baseline covariates as in Table 3, with equivalent sample sizes. (See Table A3 in Appendix 1 for subgroup sample sizes.) For each model, the F-value tests the improvement in model fit associated with the inclusion of the interaction terms. We provide the Huber-White HC3 standard errors for the subgroup-specific treatment effects. ${ }^{\text {T }}$ Indicates that this heterogeneous variable/subgroup was not pre-registered and is exploratory. 


\section{Table 6:}

Treatment-on-the-treated (TOT) estimates for the effect of receiving any FFWS aid in the first semester on the primary outcomes (percentage point changes)

\begin{tabular}{lccccc}
\hline & \multicolumn{2}{c}{ Two-year beginners } & \multicolumn{2}{c}{ Four-year beginners } \\
& Cohorts & TOT Est. & $p$-value & TOT Est. & $p$-value \\
\hline Two-year & & & & & \\
persistence & $2009-2015$ & 1.97 & 0.323 & 2.16 & 0.007 \\
& & $(1.99)$ & & $(0.80)$ & \\
Six-year bachelor's & $2009-2011$ & 0.30 & 0.919 & 2.46 & 0.128 \\
& & $(2.95)$ & & $(1.61)$ & \\
& &
\end{tabular}

Notes: Estimates based on Frölich and Melly's (2013, p. 9) weighted specification. Sample sizes for four-year beginners are equivalent to those found in Table 3. Two-year beginner models only use UWS students due to a lack of FFWS aid receipt data for technical college students. The two-year UWS (i.e., community college) sample sizes are shown in Appendix 1 in Tables A2 and A3. Bootstrapped (10,000 replications) standard errors in parentheses. 


\section{Appendix 1: Additional Tables}

\section{Table A1:}

Estimated intent-to-treat effects of FFWS grant offers on primary and secondary outcomes (percentage point changes) using Lin's (2013) approach

\begin{tabular}{|c|c|c|c|c|c|c|c|c|c|}
\hline & \multirow[t]{2}{*}{ Cohorts } & \multicolumn{4}{|c|}{ Two-year beginners } & \multicolumn{4}{|c|}{ Four-year beginners } \\
\hline & & $\begin{array}{c}\text { Control } \\
\text { Rate }\end{array}$ & $\begin{array}{c}\text { Treatment } \\
\text { Effect }\end{array}$ & $p$-value & $N$ & $\begin{array}{c}\text { Control } \\
\text { Rate }\end{array}$ & $\begin{array}{c}\text { Treatment } \\
\text { Effect }\end{array}$ & $p$-value & $N$ \\
\hline \multicolumn{10}{|l|}{ Primary outcomes } \\
\hline Two-year persistence & 2009-15 & $50.1 \%$ & $\begin{array}{c}1.20 \\
(0.80)\end{array}$ & 0.169 & 18,775 & $79.5 \%$ & $\begin{array}{c}1.70 \\
(0.70)\end{array}$ & 0.011 & 29,910 \\
\hline Six-year bachelor’s & 2009-11 & $10.3 \%$ & $\begin{array}{c}0.40 \\
(0.80)\end{array}$ & 0.584 & 8,519 & $53.4 \%$ & $\begin{array}{c}1.40 \\
(1.30)\end{array}$ & 0.270 & 13,660 \\
\hline $\begin{array}{l}\text { Secondary outcomes } \\
\text { Three-year associate's }\end{array}$ & 2009-14 & $15.1 \%$ & $\begin{array}{l}-0.40 \\
(0.70)\end{array}$ & 0.558 & 16,736 & - & - & - & - \\
\hline $\begin{array}{l}\text { Transfer to four-year } \\
\text { within three years }\end{array}$ & 2009-14 & $16.7 \%$ & $\begin{array}{l}-0.10 \\
(0.70)\end{array}$ & 0.914 & 16,736 & - & - & - & - \\
\hline Four-year bachelor’s & 2009-13 & - & - & - & - & $21.6 \%$ & $\begin{array}{l}-0.10 \\
(0.80)\end{array}$ & 0.909 & 21,929 \\
\hline
\end{tabular}

Notes: Models estimate outcomes by interacting treatment assignment with all of the mean-centered covariates (Lin, 2013). Huber-White HC3 adjusted standard errors are shown in parentheses. 


\section{Table A2:}

Estimated intent-to-treat effects of FFWS grant offers on primary and secondary outcomes (percentage point changes) using University of Wisconsin Systems data versus National Student Clearinghouse data

\begin{tabular}{|c|c|c|c|c|c|c|c|c|c|}
\hline & \multicolumn{9}{|c|}{ Two-Year Beginners } \\
\hline & \multirow[t]{2}{*}{ Cohorts } & \multicolumn{4}{|c|}{ UWS data } & \multicolumn{4}{|c|}{ NSC data } \\
\hline & & $\begin{array}{c}\text { Control } \\
\text { Rate }\end{array}$ & $\begin{array}{c}\text { Treatment } \\
\text { Effect }\end{array}$ & p-value & $N$ & $\begin{array}{c}\text { Control } \\
\text { Rate }\end{array}$ & $\begin{array}{c}\text { Treatment } \\
\text { Effect }\end{array}$ & p-value & $N$ \\
\hline \multicolumn{10}{|l|}{ Primary outcomes } \\
\hline Two-year persistence & 2009-15 & $65.5 \%$ & $\begin{array}{c}0.30 \\
(1.50)\end{array}$ & 0.820 & 5,715 & $50.1 \%$ & $\begin{array}{c}1.20 \\
(0.80)\end{array}$ & 0.138 & 18,775 \\
\hline Six-year bachelor's & 2009-11 & $24.4 \%$ & $\begin{array}{l}-0.50 \\
(2.20)\end{array}$ & 0.830 & 2,374 & $10.3 \%$ & $\begin{array}{c}0.50 \\
(0.80)\end{array}$ & 0.545 & 8,519 \\
\hline \multicolumn{10}{|l|}{ Secondary outcomes } \\
\hline Three-year associate's & 2009-14 & $22.7 \%$ & $\begin{array}{l}-2.20 \\
(1.40)\end{array}$ & 0.111 & 5,073 & $15.1 \%$ & $\begin{array}{l}-0.30 \\
(0.60)\end{array}$ & 0.693 & 16,736 \\
\hline $\begin{array}{l}\text { Transfer to four-year } \\
\text { within three years }\end{array}$ & 2009-14 & $29.8 \%$ & $\begin{array}{c}0.10 \\
(1.50)\end{array}$ & 0.926 & 5,073 & $16.7 \%$ & $\begin{array}{c}0.00 \\
(0.70)\end{array}$ & 0.965 & 16,736 \\
\hline \multirow[t]{4}{*}{ Four-year bachelor’s } & 2009-13 & - & - & - & - & - & - & - & - \\
\hline & \multicolumn{9}{|c|}{ Four-Year Beginners } \\
\hline & Cohorts & & UWS & ata & & & NSC & ata & \\
\hline & & $\begin{array}{c}\text { Control } \\
\text { Rate }\end{array}$ & $\begin{array}{c}\text { Treatment } \\
\text { Effect }\end{array}$ & p-value & $N$ & $\begin{array}{c}\text { Control } \\
\text { Rate }\end{array}$ & $\begin{array}{c}\text { Treatment } \\
\text { Effect }\end{array}$ & p-value & $N$ \\
\hline \multicolumn{10}{|l|}{ Primary outcomes } \\
\hline Two-year persistence & 2009-15 & $81.0 \%$ & $\begin{array}{c}2.30 \\
(0.60)\end{array}$ & 0.000 & 29,910 & $79.5 \%$ & $\begin{array}{c}1.70 \\
(0.70)\end{array}$ & 0.011 & 29,910 \\
\hline Six-year bachelor’s & 2009-11 & $56.2 \%$ & $\begin{array}{c}2.10 \\
(1.30)\end{array}$ & 0.102 & 13,660 & $53.4 \%$ & $\begin{array}{c}1.50 \\
(1.30)\end{array}$ & 0.254 & 13,660 \\
\hline \multicolumn{10}{|l|}{ Secondary outcomes } \\
\hline Three-year associate's & 2009-14 & - & - & - & - & - & - & - & - \\
\hline $\begin{array}{l}\text { Transfer to four-year } \\
\text { within three years }\end{array}$ & 2009-14 & - & - & - & - & - & - & - & - \\
\hline Four-year bachelor’s & 2009-13 & $21.2 \%$ & $\begin{array}{c}0.20 \\
(0.80)\end{array}$ & 0.793 & 21,929 & $21.6 \%$ & $\begin{array}{c}0.00 \\
(0.80)\end{array}$ & 0.998 & 21,929 \\
\hline
\end{tabular}

Notes: Models estimate outcomes using the model described in the methods section. Note that the two-year models only include students from UW Systems two-year colleges because technical college students do not have records in the UW Systems database. As such, persistence and graduation rates tend to be higher in the UW Systems two-year models compared to the NSC models. Huber-White HC3 adjusted standard errors are shown in parentheses. 
Table A3:

Subgroup sample sizes by college type and length of follow up

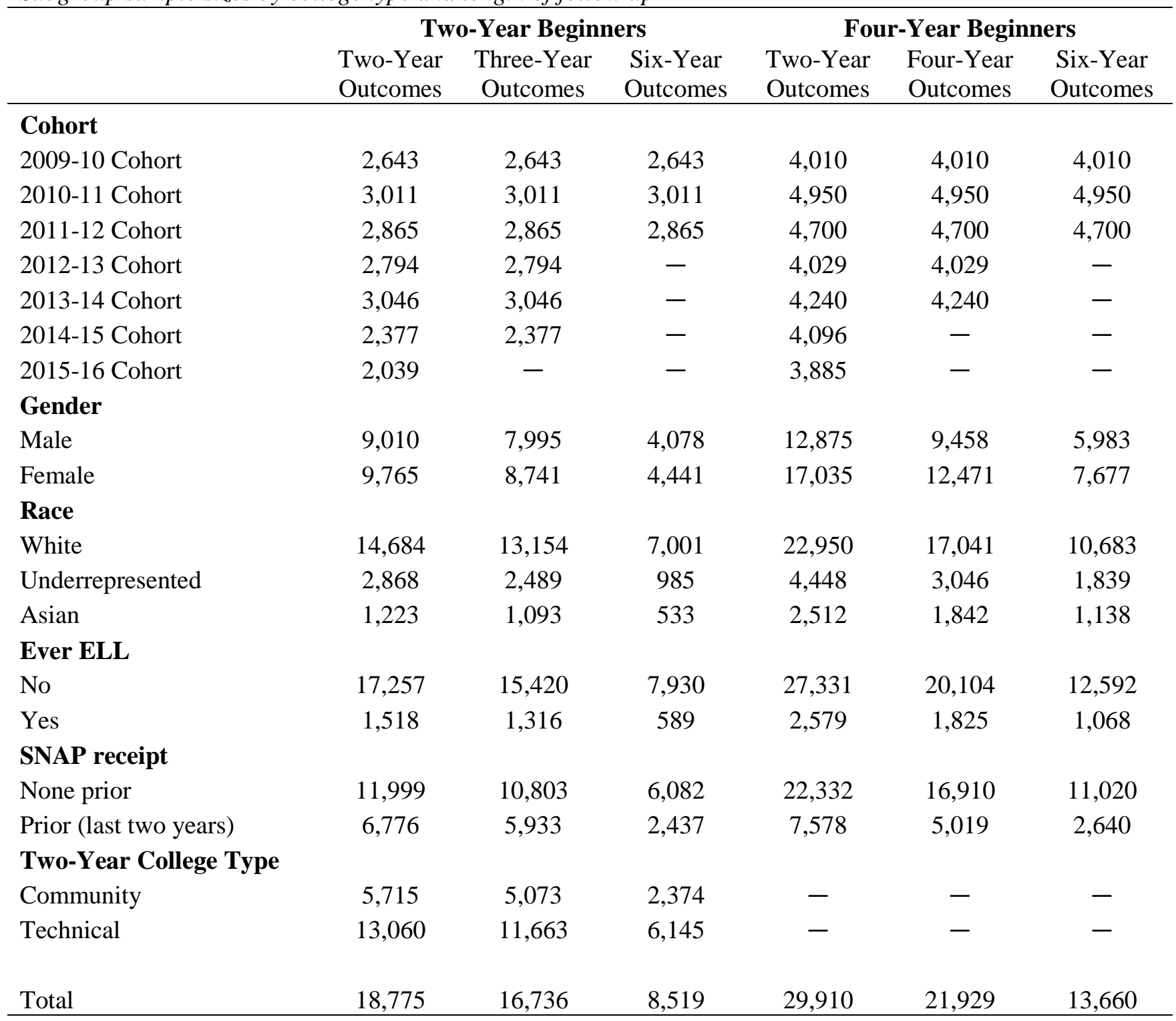

Notes: The table shows the sample sizes of each of the subgroups by college type and the length of follow-up. For example, the "Two-Year Outcomes" columns present sample sizes for models of outcomes measured two years after randomization, such as two-year persistence. Students with missing data are removed so the sample sizes correspond to the sample sizes used in Tables 3-6. 


\section{Appendix 2: Assessing Bias in the TOT Estimate}

This appendix develops a formal argument and supplementary empirical evidence for the sign and size of bias resulting from possible violations of the exclusion assumption in our TOT analysis, following a similar strategy as Heckman, Smith, and Taber (1998). Our instrumental variable analysis for the treatment effect of receiving any FFWS aid in the first semester, R, assumes that randomization of the grant offer, S, does not affect the outcomes, $\mathrm{Y}$, by any mechanism other than receiving FFWS aid. This exclusion assumption would be violated if randomization affects the outcomes via other mechanisms, such as grant acceptance, A, net of the actual disbursement of aid to the student. Here, we consider two possible mechanisms. First, students who accept the grant offer, but do not qualify for funds during their first semester, might still receive funds when they qualify in later semesters. Second, the mere possibility of receiving aid in the future might affect outcomes by fostering a sense of security, even if students never receive funds.

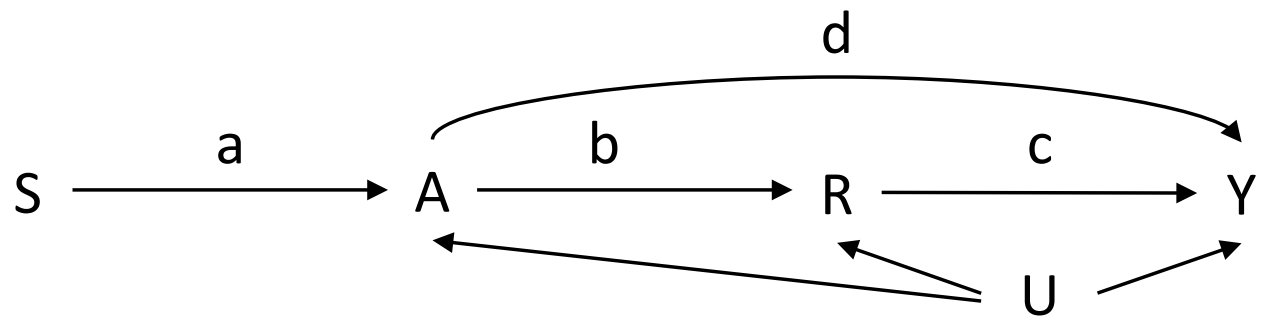

Figure A1. Graphical representation of the assumed data generating process. Because randomization, $S$, may affect the outcomes, $Y$, via grant acceptance, $A$, net of the effect via grant receipt in the first semester, $R, S$ may not be a valid instrumental variable for the treatment effect of $R$ on $Y$. The lower-case letters $(a, b, c, d)$ represent structural parameters (path coefficients).

Here, we offer arguments and empirical evidence to bound the true treatment effect of receiving FFWS aid on outcomes when exclusion is violated by these mechanisms. For simplicity, we assume a linear and homogenous model. Figure A1 is a graphical representation of the assumed structural equations, where all variables are defined as above, $S$ is randomized, 
and $\mathrm{U}$ is a vector of unmeasured confounders possibly affecting $\mathrm{A}, \mathrm{R}$ and $\mathrm{Y}$. Without loss of generality, assume that all variables are standardized, such that the structural parameters are inside the interval $[-1,1]$. (Adding the blocking variables does not change the argument.)

The usual instrumental variables estimator for the effect of $R$ on $Y$ is $c_{I V}=\frac{\operatorname{Cov}(S, Y)}{\operatorname{Cov}(S, R)}$. If grant acceptance does not affect the outcomes, $d=0$, then this estimator is consistent and converges in probability on the true treatment effect, $\hat{c}_{i v} \rightarrow \frac{a b c}{a b}=c$. If, by contrast, grant acceptance affects the outcome directly, $d \neq 0$, then the instrumental variables estimator is inconsistent and converges on $\hat{c}_{i v} \rightarrow \frac{a b c+a d}{a b}=c+\frac{d}{b}$, where $\frac{d}{b}$ is the bias term.

Since we do not observe $A$, we cannot directly estimate $d, b$, or $\frac{d}{b}$. But because the effect of grant acceptance on grant receipt is certainly positive, $b>0$, and the direct effect of grant acceptance on the outcome is, by the arguments above, likely positive, $d>0$, the bias term is likely positive, too, $\frac{d}{b}>0$. Hence, our results for the effect of actually receiving FFWS funds on the outcomes are likely upwardly biased.

\section{Table A4:}

Number of students who received grant offers and subsequently received grant funds

\begin{tabular}{|c|c|c|c|c|c|c|c|c|}
\hline & \multicolumn{4}{|c|}{ 2009-2012 Cohorts } & \multicolumn{4}{|c|}{ 2009-2015 Cohorts } \\
\hline & \multicolumn{2}{|c|}{ Two-Year } & \multicolumn{2}{|c|}{ Four-Year } & \multicolumn{2}{|c|}{ Two-Year } & \multicolumn{2}{|c|}{ Four-Year } \\
\hline & $\mathrm{N}$ & $\%$ & $\mathrm{~N}$ & $\%$ & $\mathrm{~N}$ & $\%$ & $\mathrm{~N}$ & $\%$ \\
\hline Received the grant offer & 714 & $100 \%$ & 2,296 & $100 \%$ & 1,387 & $100 \%$ & 3,993 & $100 \%$ \\
\hline $\begin{array}{l}\text { Received grant funds in } \\
\text { the first semester }\end{array}$ & 503 & $70 \%$ & 1,902 & $83 \%$ & 1,019 & $73 \%$ & 3,356 & $84 \%$ \\
\hline $\begin{array}{l}\text { Received grant funds } \\
\text { within } 5 \text { years }\end{array}$ & 503 & $70 \%$ & 1,912 & $83 \%$ & - & - & - & - \\
\hline
\end{tabular}

Notes: The sample sizes are calculated using the full set of available data from the UW System two- and fouryear treatment group samples. 
The size of the bias, however, may be small because $b$ is likely much larger than $d$. We discuss this logic using the example outcome of persistence into the second year for four-year students, but the logic and conclusions are the same for other outcomes and two-year students. First, we bound $b$. Table A4 shows the relationship between the randomized grant offer and disbursement of grant funds. In four-year institutions, 84.0 percent of students who were randomized to a grant offer received funds during the first semester. If all students who were randomized to offer receipt accepted the offer, the lower bound for $b$ is 0.84 . If some students who were randomized to receive an offer did not accept the offer, the upper bound for $b$ is 1.00 .

Next, we bound $d$. Since Table A4 also shows that virtually all students who ever received funds received them during their first semester, the possible direct effect of grant acceptance on outcomes would have to operate via psychological mechanisms rather than the receipt of funds in later semesters. It is plausible that the effect of these psychological mechanisms on college persistence, $d$, is small, and certainly no larger than the effect of receiving $\$ 3,500$ to $\$ 4,000$ dollars in aid on the treated, $c$, such that $0 \leq \frac{d}{c} \leq 1$

To calculate bias-corrected estimates of the effect of receipt of FFWS aid in the first semester $(c)$, we use the following formula, which is derived from the equation above after substituting $d=p c$ :

$$
c=\frac{b \hat{c}_{i v}}{b+p}
$$

where $p=\frac{d}{c}$, the ratio of the direct effect of grant acceptance to the effect of grant aid receipt, $b$ is equal to the effect of grant acceptance on grant receipt in the first semester, and $\hat{c}_{i v}$ is the IV estimate of the effect of grant receipt in the first semester on the outcome. 
Figure A2 shows bias-corrected estimates for the effect of receiving funds during the first semester on persistence into the second year of college among students in four-year institutions. The estimates range across values of $b$ for different assumptions about the ratio between the direct psychological effects and financial effects of grant acceptance on the outcome, $\frac{d}{c}$. We see that $b$ - the effect of grant acceptance on the receipt of grant funds in the first semester-has very little impact on the estimate over the range of possible values of $b$. The main mechanism that could bias the estimated TOT effect is $d$-the direct effect of grant acceptance on the outcome. If the exclusion restriction holds (i.e., there is no direct effect of grant acceptance and $\frac{d}{c}=0$ ), the estimate is unbiased (a 2.2 percentage-point increase in persistence). If we assume that the direct effect of grant acceptance on the outcome is equal to the effect of the receipt of grant aid in the first semester (i.e., $\frac{d}{c}=1$ ), then our reported instrumental-variables estimate is upwardly biased by a factor of 2 and the actual treatment effect of grant receipt is as low as a 1 percentage point increase in persistence. However, it seems unlikely that the psychological effect of accepting a grant offer could equal the monetary impact of \$3,500 to \$4,000 of aid. Even if we allow $d$ to be 20 percent of $c$, the treatment effect of grant receipt is still almost 1.8 percentage points, and the 95 percent confidence interval (based on the standard errors of the TOT analysis_-see Table 6) does not include 0 . In fact, $d$ can be up to 33 percent of $c$ and the biasedcorrected estimate would remain statistically significant at the 0.05 level. This exercise, therefore, suggests that the substantive conclusions of our TOT analysis are robust to reasonable violations of the exclusion restriction. 


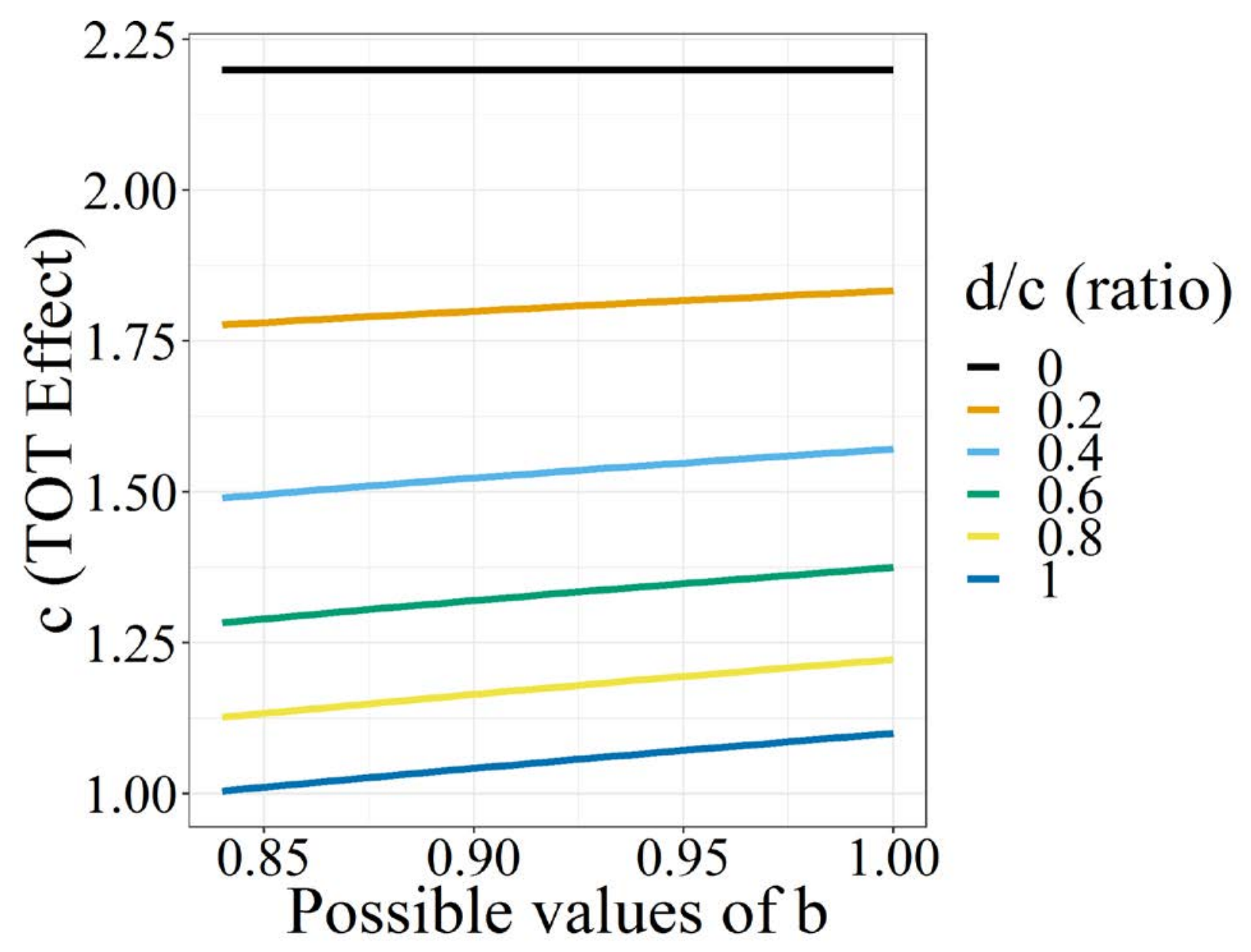

Figure A2. The figure provides bounded bias-corrected estimates for the TOT effect (c) on persistence for four-year students over different values of $d$ and $b$. As discussed in the text, $d$ represents the direct effect of grant acceptance on student outcomes and $b$ represents the effect of grant acceptance on grant aid receipt in the first semester. For this analysis, we assume that $d$ is positive. (I.e., we assume that, if anything, grant acceptance causes an increase in persistence and degree completion.) We allow the size of $d$ to vary in relation to the size of $c$. The values range from 0 (the ratio of $d$ to $c$ equals 0 - there is no direct effect of grant acceptance on the outcome) to 1 (the ratio of $d$ to $c$ equals 1 -the direct effect of grant acceptance on the outcome is equal to the effect of the receipt of grant aid in the first semester on the outcome). We also allow $b$ to vary over all possible values. Because around 84 percent of students receive grant aid in the first semester, the relationship between grant acceptance and grant receipt in the first semester must be greater than or equal to 0.84 . 


\section{Endnotes}

${ }^{1}$ American Economic Association's registry for randomized control trials RCT ID number: AEARCTR-0003198. Registered on September 18, 2018.

${ }^{2}$ Note that Bettinger et al. (2019) examine the Cal Grant, which provides financial assistance to low-income students who meet minimum GPA requirements in high school (currently a GPA of 3.0).

${ }^{3}$ Because the STBF study randomizes high school students prior to college enrollment, the study samples are actually 1) students who intended to attend two-year schools and 2) students who intended to attend four-year schools. Here, we call them two- and four-year college students for simplicity. Angrist et al. (2016) also found that the STBF program improved college enrollment rates for both samples of students.

${ }^{4}$ Email correspondence with the data-linking team at the Institute for Research on Poverty (June 18, 2019).

${ }^{5}$ Email correspondence with the Fund for Wisconsin Scholars (June 18, 2019).

${ }^{6}$ Email correspondence with the Fund for Wisconsin Scholars (June 18, 2019).

${ }^{7}$ The pre-analysis plan specified 49,823 observations. Subsequent inspection revealed that some observations were identical duplicates. Removal of duplicates yields a final sample of 49,807 observations referring to 49,807 randomizations of 48,804 students.

${ }^{8}$ This coding scheme differs from the pre-specified document in that we pre-registered the use of semester-bysemester records to code the persistence variable. Because records were only available by enrollment date, we used the above scheme to measure enrollment in a given semester.

${ }^{9}$ DPI records do not separately identify Hmong students, who are considered an underrepresented group in Wisconsin. Hmong students are thus presumably included in the "Asian" category. In addition, we originally preregistered an "Other" racial category to include Asian students and students in the "two or more" category. However, our data include no students in the latter category.

${ }^{10}$ This coding scheme differs slightly from our pre-analysis plan, which proposed measuring SNAP receipt in the last two years of high school. Since not all students had clearly defined high school graduation dates in the DPI data, we measured SNAP receipt during the two years prior to randomization. For example, for students randomized in the 2009-10 school year, we measure whether their household of residence received any SNAP funds in 2007 or 2008.

${ }^{11}$ Email correspondence with the Fund for Wisconsin Scholars (June 18, 2019).

${ }^{12}$ Our pre-analysis plan specified that we would estimate the probability of being in the treatment group conditional on cohort, race, gender, and ELL status. However, we decided to estimate the probability conditional on only cohort because treatment status is independent of race, gender, and ELL status in the population due to randomization.

13 The pre-registered primary specification shown in Table 3 assumes constant effects across groups defined by the covariates. If the treatment effect varies across groups, and if - by chance- the proportion of treated students varies across groups, then our specification would give a variance-weighted, rather than an unweighted, average treatment effect across students. To test the robustness of our results, we also estimate Lin's (2013) estimator that fully interacts treatment with mean-centered covariates and then averages across groups. Results (Appendix Table A1) are quantitatively very similar and qualitatively unchanged. 